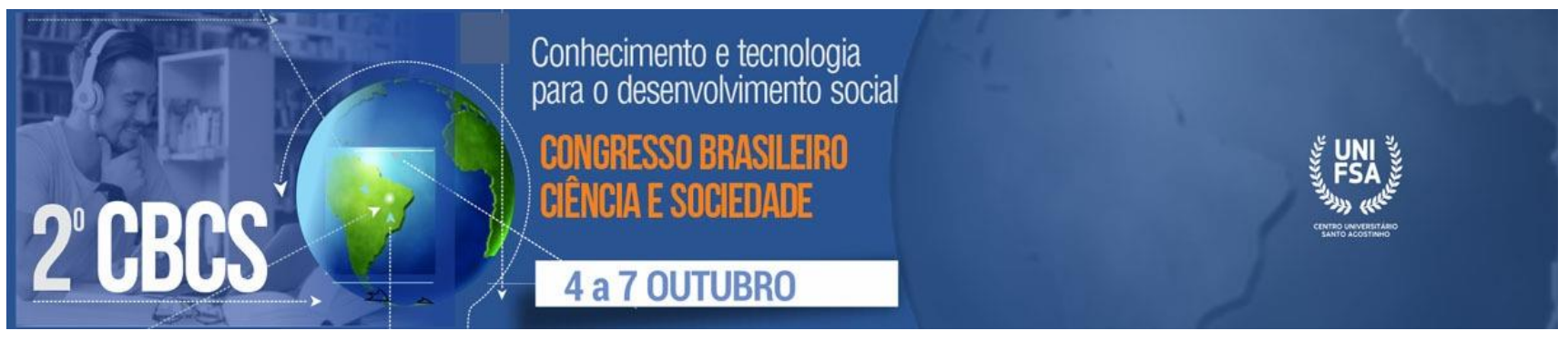

\title{
COVID-19 E AS COMORBIDADES NOS PACIENTES MENORES DE 60 ANOS INTERNADOS EM UM HOSPITAL DE REFERÊNCIA.
}

\author{
Lucia Emanuele de Sousa Silva ${ }^{1}$ \\ Neylany Raquel Ferreira da Silva ${ }^{2}$ \\ Claudionayra Sousa Duarte ${ }^{3}$ \\ Everton Carvalho Costa ${ }^{4}$ \\ Bárbara Pereira Gomes ${ }^{5}$ \\ Edilson Carvalho de Sousa Júnior ${ }^{6}$
}

\section{RESUMO}

O objetivo foi avaliar as comorbidades em pacientes com idade inferior a 60 anos com covid-19, internados em Unidade de Terapia Intensiva (UTI). Trata-se de um estudo descritivo, retrospectivo, documental e com abordagem quantitativa, realizado no período de março a junho de 2020 . O projeto foi aprovado pelo Comitê de Ética da instituição hospitalar, sob parecer n. 4.240.951 e CAEE 34720820.8.0000.5584. O estudo permitiu identificar 74 pacientes com idade inferior a 60 anos internados por COVID-19. Deste quantitativo, $43 \%$ constituía-se do sexo masculino e $57 \%$ do sexo feminino. O perfil das comorbidades e sintomatologia mais prevalentes nos pacientes com COVID19 foram: tosse $(55,5 \%)$ febre, $(54 \%)$, mialgia $(48,5 \%)$, cefaleia $(48 \%)$, e dispneia $(42 \%)$. A relevância dos resultados apresentados nesta pesquisa é útil na identificação das comorbidades que foram predominantes em pacientes com idade inferior a 60 anos, ainda no início dos casos de COVID-19 em Teresina, Piauí.

Palavras-Chave: Pandemia; Covid-19; Comorbidade.

\section{INTRODUÇÃO}

A Organização Mundial de Saúde (OMS) em março de 2020, caracterizou como pandemia, a doença causada pelo novo coronavírus SARS-CoV-2 (covid-19), oque levou os serviços de saúde a um novo cenário e segurança voltada aos profissionais envolvidos nos cuidados aos pacientes $^{1-2}$. O vírus SARS- CoV-2, pertence à espécie SARS-like coronavírus de $125 \mathrm{~nm}$, sendo ligeiramente maior e mais potente que os vírus influenza, SARS e MERS. Este novo

\footnotetext{
${ }^{1}$ Trabalho apresentado no 2ㅇ Congresso Brasileiro Ciência e Sociedade (CBS 2021), promovido pelo Centro Universitário Santo Agostinho, de 04 a 07 de outubro de 2021, em Teresina-PI.

${ }^{2}$ Graduanda em Enfermagem pelo Centro Universitário Uninassau; Mestranda em Saúde e Comunidade (UFPI); Graduanda em Engenharia de Produção (UFPI); Graduado em Enfermagem pela Instituição de Ensino Superior Multiplo (IESM); Graduanda em Enfermagem pelo Centro Universitário Unifacid Wyden; Doutorado, Universidade Estadual do Ceará (UECE) e diretor do Centro de Ensino e Pesquisa HSM.
} 
coronavírus compartilha cerca de $79,5 \%$ da sequência genética com SARS-CoV e 96,2\% de homologia com o coronavírus pertencentes aos morcegos, sugestivo do vírus Rhinolophus, indicando uma provável descendência ${ }^{3}$.

A transmissão da covid-19 se propaga, principalmente, por gotículas, secreções e/ou partículas de aerossóis respiratórios de pessoas que contraíram o vírus, além de contato com superfícies inanimadas contaminadas ${ }^{4}$. Além disso, a transmissão do SARS-CoV-2 é agravada pelo elevado tempo médio de incubação, cerca de 5-6 dias (variando de 0 a 24 dias), e devido a pessoas assintomáticas, pré-sintomáticas ou com sintomas leves poderem transmitir a doença $a^{5}$.

Frente a esse cenário de pandemia, muitos hospitais no mundo se adequaram na reorganização dos atendimentos, contratação de profissionais qualificados, abastecimento de equipamentos de proteção individual, insumos emateriais hospitalares, além da ampliação suficiente de leitos em unidades de terapia intensiva ${ }^{6}$.

Ressalta-se que diante de repercussões hemodinâmicas mais graves, relacionado ao paciente com covid, é necessário suporte e tratamento intensivos, sob cuidados dos profissionais de saúde multidisciplinares ${ }^{7}$. Estudos evidenciaram que pacientes admitidos em Unidade de Terapia Intensiva (UTI) a prevalência de comorbidades como diabetes mellitus (DM) e doenças cardiovasculares (DCV) em síndrome respiratória aguda (SARS) foi de 11\% e $8 \%$, respectivamente, e a presença destas doenças estava associada a um risco elevado de morte relacionado com o coronavírus ${ }^{8}$. Assim, o objetivo deste estudo é avaliar a covid-19 e as comorbidades em pacientes menores de 60 anos internados em um hospital de referência.

\section{METODOLOGIA}

Trata-se de um estudo descritivo, retrospectivo, documental e com abordagem quantitativa, realizado em um hospital de referência para tratamento em oncologia e serviços de alta complexidade no atendimento à saúde no estado do Piauí.

A instituição possui mais 232 leitos de internação, 05 UTIs, 13 postos de internação, 01 Pronto Atendimento (PA), além do setor de radioterapia equimioterapia pediátrica e adulto, 01 centro cirúrgico, hemodinâmica, hemodiálise, radiologia com atendimento voltados ao tratamento, diagnóstico, exames, consultase atendimento ao público não somente da região do Piauí, mas de outras localidadesNorte e Nordeste. 
Os critérios de inclusão foram os pacientes internados em unidade de terapia intensiva, com idade inferior a 60 anos e que fossem portadores de comorbidades. E os critérios de exclusão foram os prontuários preenchidos de forma incompleta que não estavam dentro dos meses de março a junho de 2020.

A coleta ocorreu no mês de dezembro de 2020, onde incluiu 74 pacientes internados na UTI COVID, o acesso foi por meio de dados secundários (prontuário) eletrônico, disponibilizados pelo Centro de Processamento de Dados (CPD) da instituição em local e horário previamente combinados. Os dados coletados neste estudo foi delimitado para os meses de março a junho de 2020, onde iniciou-se as internações e casos de covid-19 no estado do Piauí.

Mediante aos dados coletados, os resultados das quantitativas foram organizados, descritos e sintetizados para o programa Microsoft Excel, para a realização de análise estatística através de números absolutos e percentuais e, posteriormente, realizada a confecção dos gráficos.

Os pesquisadores obedeceram às recomendações éticas dispostas nas diretrizes e normas vigentes para pesquisas envolvendo seres humanos, determinada na Resolução no 466/2012 do Conselho Nacional de Saúde. O projeto foi aprovado pelo Comitê de Ética da instituição hospitalar, sob parecer № 4.240.951 e CAEE 34720820.8.0000.5584

\section{RESULTADOS E DISCUSSÃO}

As doenças crônicas não transmissíveis, são caraterizadas como um dos desafios supremos da saúde pública em todo o mundo. Sendo mais evidenciado no contexto pandêmico originado pelo novo coronavirus. Diabetes, Hipertensão Arterial Sistêmica (HAS), e Doenças Respiratórias Crônicas, mais são as patologias correlacionadas as notificações, internações, ocupações de leitos em Unidade de Terapia Intensiva (UTI), e óbitos, relacionados a covid-19, podendo coexistir em um mesmo individuo.

Dentre os grupos de riscos, destacam-se adultos, idosos e pesssoas com histórico de doenças e comorbidades pregressas as quais agravam o quadro clínico da doença, somandose $a$ isso a senilidade, podendo agudizar os sintomas. A sintomatologia da covid-19, é variada destacando-se, artralgia, tosse seca, febre e dispnéia, sendo o maior agravo do Sars-CoV-2, gerando a necessidade de internação em UTI, a depender do grau de dificuldade respiratória 
do paciente.

Com base nos dados coletados, dentre os meses pesquisados, em junho de 2020 foi o período onde mais obteve admissões na UTI COVID da instituição com $56,6 \%$ das internações. Com relação às idades, os pacientes com 57 anos tiveram uma maior predominância, seguida dos pacientes com 37, 36 e 30 anos. No processo de admissão o perfil das comorbidades e sintomatologia mais prevalentes nos pacientes com covid-19 foram tosse (55,5\%), febre (54\%), mialgia (48,5\%), cefaléia (48\%) e dispneia (42\%). O estudo permitiu identificar 74 pacientes menores de 60 anos internados por covid-19. Destes $43 \%$ eram do sexo masculino e $57 \%$ do sexo feminino. Em relação às comorbidades houve um predomínio de $55 \%$ em pacientes com hipertensão arterial, seguido por obesidade com $42,2 \%$ em pacientes com obesidade.

O tempo de internação é ajustado de acordo com o quadro clínico do paciente, podendo variar de dias à meses de hospitalização. Em geral,os pacientes recebem alta da UTI e seguem para as unidade de internação, onde finalizam o período de recuperação. Por fim, os números de óbitosem UTI por covid-19 que obtinha alguma comorbidade foram mínimos, totalizando-se em 02 óbitos no período da coleta. 
Os dados contidos no gráfico 1, apresenta o aumento de casos para covid-19, ainda no inicio dos primeiros casos durante internação de pacientes no Hospital de Teresina, Piauí. No mês de março apenas um paciente foi registrado, sendo assim, ao decorrer dos meses os números foram obtendo crescimento, proporcionando uma série de investimentos governamentais e restrições a população em geral.

IMAGEM 1. Casos de COVID-19 referente a março a junho de 2020. Teresina (PI), Brasil, 2020.

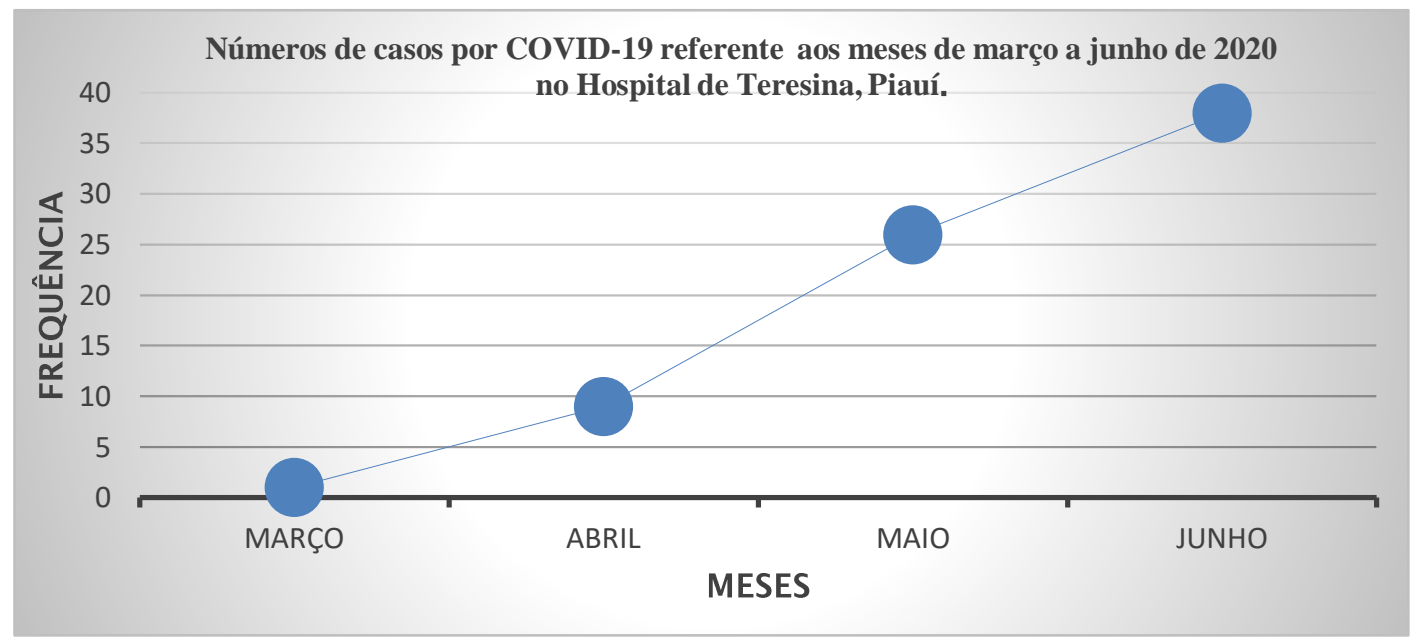

Fonte: Hospital São Marcos, 2020.

Desta forma, em menos de um mês foi registrado em abril, nove internações acometidos pelo vírus, no mês de maio obteve um salto no número de pacientes internados com covid-19, sendo registrado vinte e seis pacientes e por fim, em junho obteve-se o maior índice dentre os meses estudados, com trinta e nove internações no referido Hospital. 
De acordo com o gráfico 2, foi possível identificar as faixas etárias dos pacientes que foram internados no Hospital de Teresina nos meses de março a junho de 2020. É possível obervar que determinadas faixas etárias ganham destaque no número de internações, os pacientes com idade de 57 anos estão entre os mais acometidos, seguida dos pacientes com 37,36 e 30 anos.

IMAGEM 2. Casos de covid-19 internados por faixa etária, Teresina (PI), Brasil, 2020.

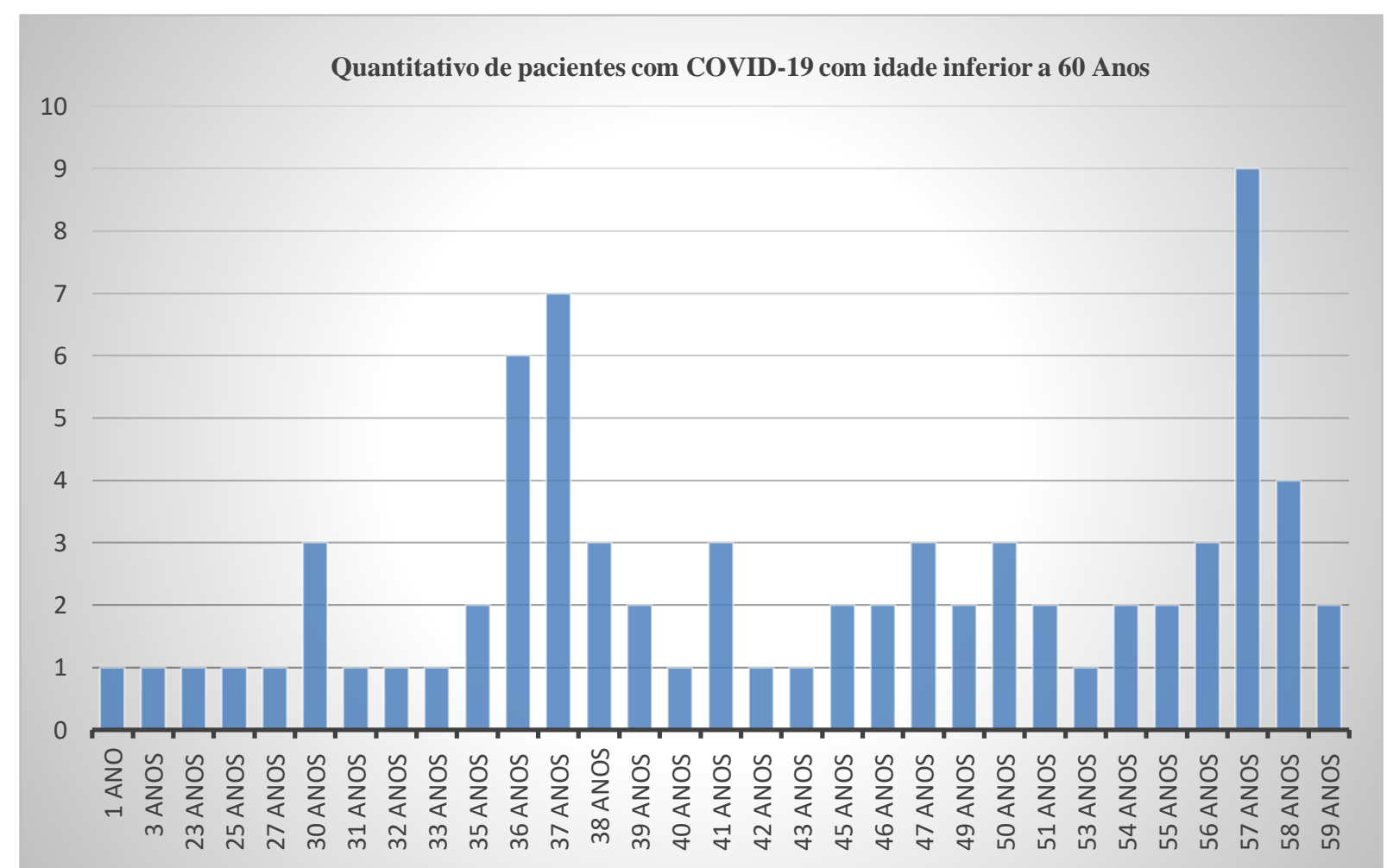

Fonte: Hospital São Marcos 
Em relação aos dados clínicos dos pacientes hospitalizados por covid-19, foi possível observar que a tosse esteve presente em $55 \%$ dos pacientes, sendo o sintoma mais prevalente, seguido da febre, dispneia e insuficiência respiratória, a perda de olfato, paladar e hiporexia se enquadraram como um dos sintomas menos presente conforme consta no gráfico 3.

IMAGEM 3. Distribuição de dados clínicos dos sintomas em pacientes internados com COVID, Teresina (PI), Brasil, 2020.

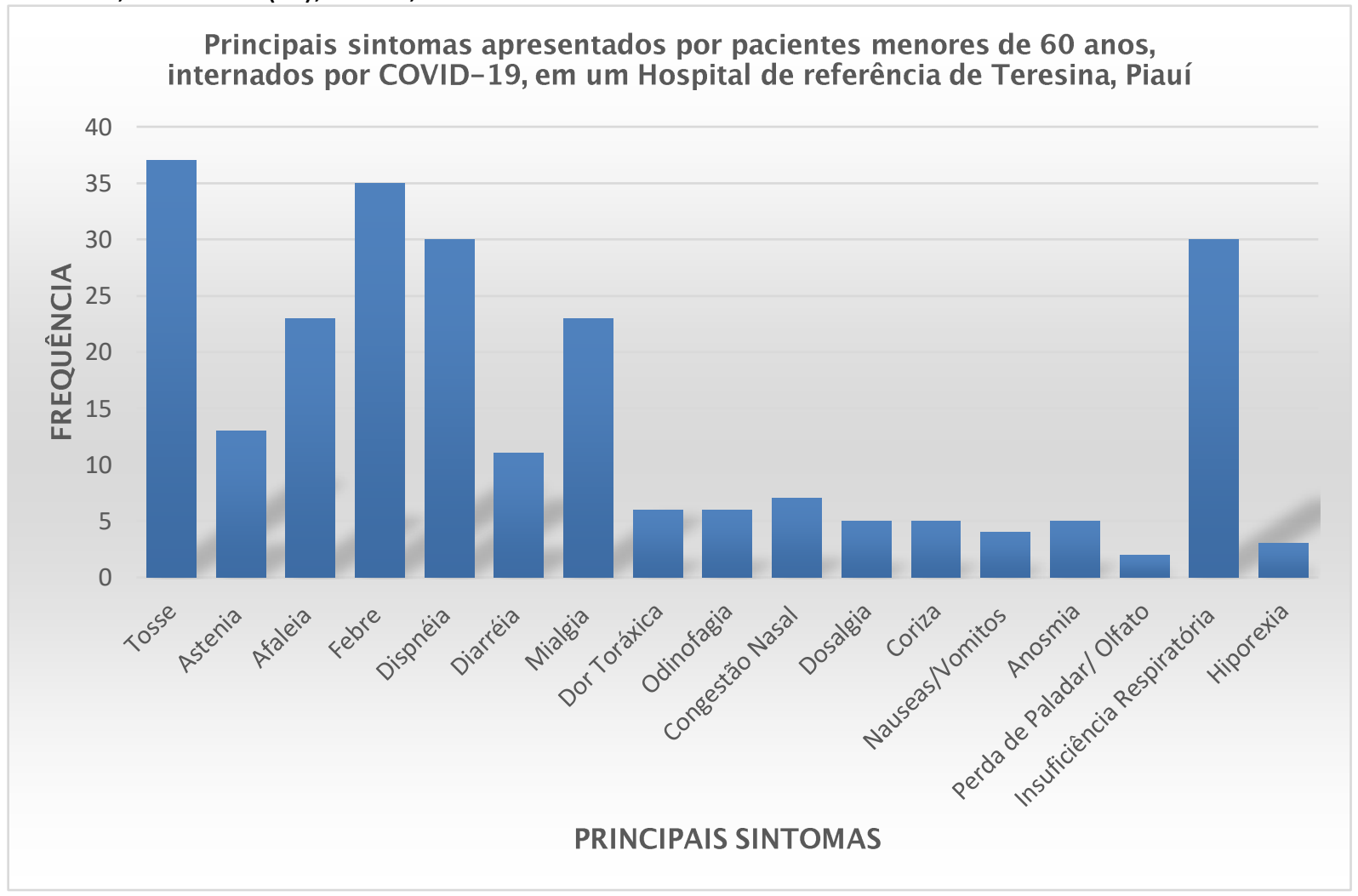

Fonte: Hospital São Marcos, 2020. 
A prevalência da hipertensão arterial entre os pacientes hospitalizados com idade de 30 a 59 anos, foi a que teve um quantitativo maior comparado as demais comorbidades e faixas etárias em pacientes com covid-19 conforme gráfico 4, seguido por obesidade com 11 pacientes, diabetes mellitus 3 e asma com 5 pacientes.

IMAGEM 4. Principais comorbidades apresentadas por pacientes menores de 60 anos internados por COVID-19, Teresina (PI), Brasil, 2020.

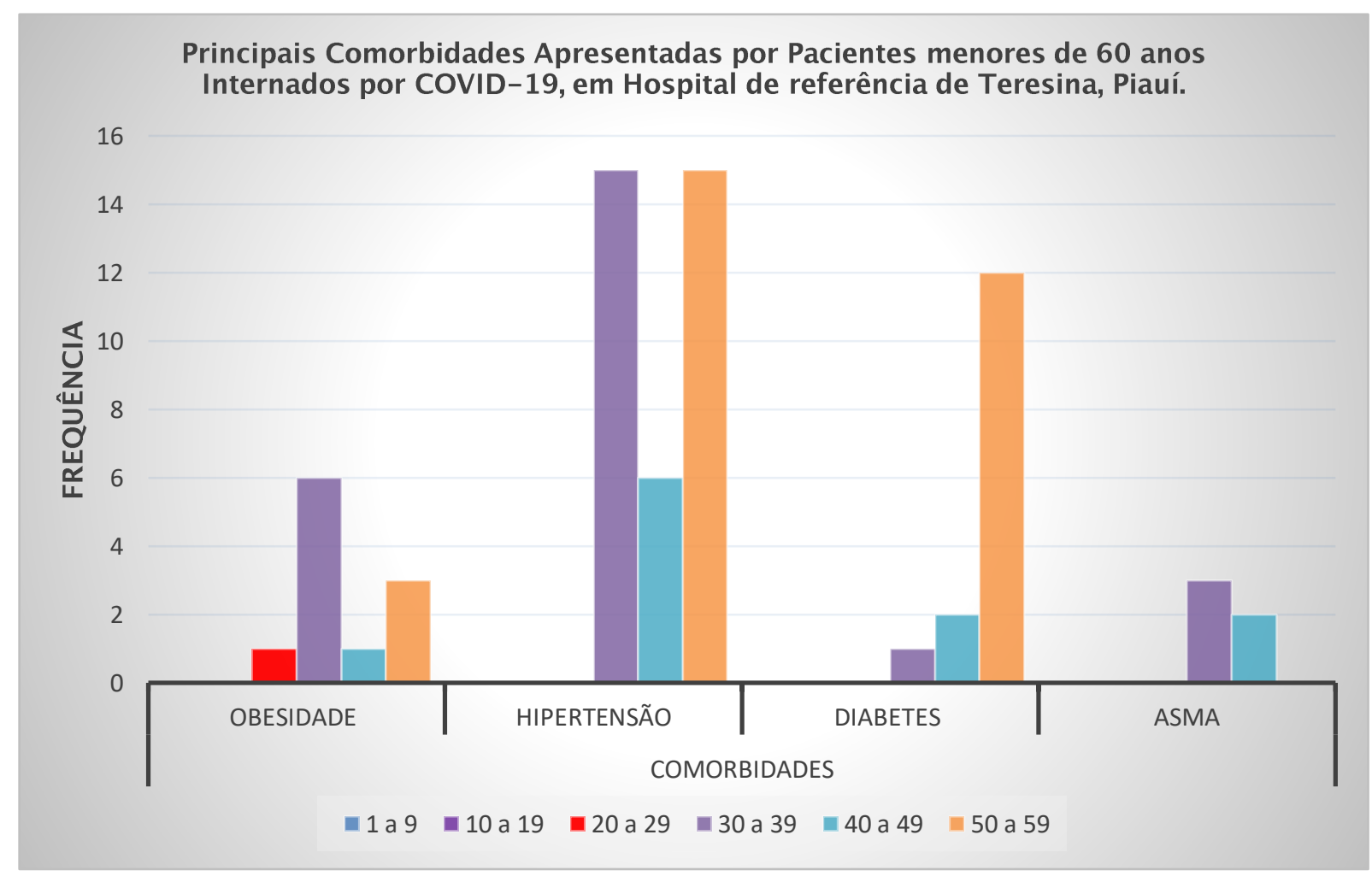

Fonte: Hospital São Marcos, 2020.

\section{CONSIDERAÇÕES FINAIS/CONCLUSÕES}

Diante da situação pandêmica, foi necessário que os hospitais buscassem implementar um plano de contingência para covid-19, a fim de instituir estratégia alinhamento de ações, a aplicação de protocolos e procedimentos padronizados para resposta ao novo Coronavírus (covid-19). 
O estudo permitiu identificar o perfil das comorbidades e sintomatologia mais prevalentes nos pacientes com covid-19 que estavam internados na UTI COVID.

Vale destacar que é um setor que exige cuidados complexos e cautelosos pelos profissionais de saúde, sendo necessário compreender as disfunções e evolução quanto à idade, gênero e complicações desses pacientes. É sabido que a disseminação do vírus se propaga de forma rápida, os números de pessoas infectadas e admitidas em unidade de terapia intensiva atualizam-se constantemente, sendo assim, a amostragem apresentada no estudo e com o quantitativo de pessoas, é correspondente ao mês de março a junho do ano de 2020.

Os resultados apresentados nesta pesquisa podem ser relevantes, principalmente, na identificação das comorbidades predominantes nos pacientes com idade inferior a 60 anos, ainda no início dos casos de covid-19 em Teresina, Piauí.

\section{REFERÊNCIAS}

1. World Health Organization. Rollings updates on coronavirus disease. 2020 [cited 2020 mar 20]. Available from: https://www.who.int/emergencies/diseases/novel-coronavirus-2019/eventsas-they-happen.

2. World Health Organization. Naming the coronavirus disease (COVID-19) and the virus that causes it. 2020 [cited 2020 mar 20]. Available from:

http://who.int/emergencies/diseases/novel-coronavirus-2019/technical-guidance/naming-thecoronavirusdisease-(COVID-2019)-and-the-virus-that-causes-it

3. Gallaschl, C.H; Cunha, M.L; Pereira, L.A.S; Silva-Junior, J.S. Prevençãorelacionada à exposição ocupacional do profissional de saúde no cenário deCOVID-19. Revista de Enfermagem UERJ, 02 de abril de 2020; acesso 11 de junho 2020:

4. BRASIL. Ministério da Saúde. Protocolo de Manejo Clínico do Coronavírus (covid-19) na Atenção Primária à Saúde. 2020. Disponível em: \&lt https://www.saude.gov.br/images/pdf/2020/marco/20/20200318-ProtocoloManejover002.pdf\&gt;. Acesso em: 29.05.2020.

5. Aquino, E.M.L; Silveira, I.H; Pescarini, J.M; Aquino, R; Souza-Filho. Medidas de distanciamento social no controle da pandemia de COVID-19: potenciais impactose desafios no Brasil. Ciênc. saúde coletiva. vol.25 supl.1 Rio de Janeiro June2020 Epub June 05, 2020.

6. Medeiros, Eduardo Alexandrino Servolo CHALLENGES IN THE FIGHT AGAINST THE COVID-19 PANDEMIC IN UNIVERSITY HOSPITALS. Revista Paulista de Pediatria [online]. 2020, v. 38 [Accessed 1 June 2021], e2020086.

7. Carelli, G.C.C; Barbosa, E.S; Taets, M.C; Bitencourt, G.R. Functional health standards in adults with COVID-19 in intensive care: a rationale for nursing diagnoses. Scielo preprint. Acesso em 15 de junho de 2020.

8. Askin, L; Tanrıverdi, O; Askin HS, O. Efeito da Doença de Coronavírus 2019 nas Doenças Cardiovasculares. Arquivos Brasileiros de Cardiologia . vol.114 no.5 SãoPaulo May 2020Epub June 01, 2020https://doi.org/10.36660/abc.20200273 Acesso em: 15 de junho de 2020. 
